\title{
Comparison of ephedrine and phenylephrine in incidence of headache during spinal anesthesia in cesarean delivery.
}

\author{
Mitra Yari, Mansour Choubsaz, Hossein Farzam, Elham Siahkamari, Parisa Golfam* \\ Department of Anesthesia, Imam Reza Hospital, Kermanshah University of Medical Sciences, Kermanshah, Iran
}

\begin{abstract}
Background: Spinal anesthesia is more acceptable method of anesthesia in elective cesarean section, but hypotension is the major limitation of this technique which might trigger to serious complications for both mother and fetus. The use of vasopressors is necessary to control hypotension caused by spinal anesthesia, however, it might be along with side effects like headache.

Methods: In the present study, 105 candidates for elective cesarean delivery were assessed to compare the role of ephedrine and phenylephrine in relation with the incidence of headache. Pearson Chi-square test, Kruskal-Wallis test, Spearman's rho correlation coefficient was performed to analyse the data. $P$ value $<0.05$ was considered significant. All data were analysed using Stata 12.

Results: The incidence of headache during the surgery was $51.4 \%, 45.7 \%$ and $37.1 \%$ in ephedrine, phenylephrine and control groups respectively. Not a significant difference was found between ephedrine and phenylephrine regarding the incidence of headache $(P=0.541)$, also no significant difference were found in the severity of the headache $(P=0.277)$. The severity of the headache was not different $24 \mathrm{~h}$ after surgery. The number of doses of vasopressor consumption in ephedrine and phenylephrine recipients was not significantly different $(P=\mathbf{0 . 5 7 9})$. No significant difference was found between the number of doses used and the severity of the headache during surgery $(P=0.979)$. However, the average of systolic blood pressure in ephedrine group was higher than phenylephrine group $(\mathrm{P}=\mathbf{0 . 0 0 1})$. Also, the impact of ephedrine and phenylephrine on heart rate was similar and affectless.

Conclusions: In this study, no significant differences were observed in the incidence and severity of headaches during and after surgery, and the number of doses of vasopressor drug consumption between phenylephrine and ephedrine recipients to treat hypotension associated with spinal anesthesia in cesarean section.
\end{abstract}

Keywords: Anesthesia, Spinal, Cesarean section, Phenylephrine, Ephedrine, Headache.

Accepted on September 23, 2017

\section{Introduction}

Spinal anesthesia, recently, has been known as an acceptable anesthesia technique, especially for cesarean section, due to advantageous on epidural anesthesia, such as rapid onset, intensity, symmetric sensory and motor block $[1,2]$. However, hypotension triggered by spinal anesthesia during cesarean delivery has been known as a common complication that might endanger the lives of both mother and fetus. So, make it necessary to use vasopressors as a treatment of hypotension [3].

Ephedrine and phenylephrine are of common vasoconstrictor drugs which their effect on hypotension during anesthesia have been compared in many studies. Although no definite difference has been observed between two drugs regarding the prevention of hypotension following spinal anesthesia [4], some preferred ephedrine because it does not increase in heart rate of the fetus, and some other preferred phenylephrine to modulate reducing placental perfusion [5-8]. Some studies have shown frequent appearance of fetal tachycardia with use of ephedrine [9], and some demonstrated the effect of phenylephrine on fetal acid base status [10]. Each vasopressor, either ephedrine or phenylephrine, undergoes pros and cons.

The function of a vasopressor is not always in same way of the other; for example, in a comparison among candidate individuals for cesarean section, mean arterial and diastolic blood pressure were only stabilized with phenylephrine, but not with ephedrine [11]. On the other hand, in the study of Loughrey et al. the simultaneous bolus administration of ephedrine and phenylephrine was compared with bolus ephedrine alone. They did not found any superiority for combination therapy than bolus injection of ephedrine in stabilizing hemodynamic subsequences of spinal anesthesia [12]. Also, it has been shown that administration of phenylephrine reduced the frontal lobe oxygenation, while infusion of ephedrine did not significantly affect the level of $\mathrm{ScO}_{2}$ [13]. Even in some cases of spinal anesthesia in cesarean section, surprisingly, no effect on hypotension was observed 
following the administration of either ephedrine or phenylephrine [14].

Some other studies have demonstrated a similar effect of ephedrine and phenylephrine on some other factors. The influence of ephedrine and phenylephrine on systolic blood pressure under spinal anesthesia was found to be equal, for both agents [11]. Furthermore, investigations on the effect of either of ephedrine and phenylephrine on placental vascular resistance did not detect any differences and supported the equal value for both of them [15]. Also, no differences were observed between the effect of ephedrine and phenylephrine on chemical components of umbilical arterial and venous [13].

All of these results demonstrate that the effects of ephedrine and phenylephrine on hemodynamic parameters and post operational condition of patients is not still clear, and superiority of each on the other has been remained controversial.

The present study aimed to compare the influence of each of ephedrine and phenylephrine on headache outcome. In addition, hemodynamic properties were assessed as complementary. For this purpose, 105 candidates for cesarean section were participated in this study to assess the potential relation between the type of vasopressor and post-operational side effects.

\section{Methods}

\section{Patients}

This clinical trial study was performed on 105 women, candidate for elective cesarean delivery (C-section), presented to Imam Reza Therapeutic Educational Center of Kermanshah in 2016 .

\section{Inclusion and exclusion criteria}

Patients (candidates) categorized in ASA classes of 1 and 2, age of 18-40, BMI range of 18.5-25, systolic blood pressure of 120 to $140 \mathrm{mmHg}$ were included into the study. Those candidates with any history of migraine, psychiatric diseases, drug using (except authorized pregnancy additives), multiple pregnancy, headache before surgery, contraindications for spinal anesthesia, pregnancy disorders like pre-eclampsia and Umbilical cord anomalies, and those with uncontrolled clinical condition, such as high blood pressure, diabetes, and cardiovascular diseases, were excluded from study. Also, patients who received Atropine, following bradycardia, and those with more than one attempt of spinal anesthesia were excluded.

\section{Performance}

Spinal anesthesia was performed in sitting position and using G25 Quincke needles in a location between L3 and L4 spines. After ensuring about Cerebrospinal Fluid (CSF) flow, $12 \mathrm{mg}$ of hyperbaric bupivacaine (Buvanest Spinal 0.5\%) was injected into the intrathecal space. Afterward, patient was kept in supine position and vital signs were monitored every $2 \mathrm{~min}$ (first $10 \mathrm{~min}$ ), then continued every $5 \mathrm{~min}$. When patient had a series of two or more episodes of systolic blood pressure decrease below $80 \%$ of baseline (hypotension) $15,10 \mathrm{mg}$ bolus of ephedrine (ephedrine HCL $50 \mathrm{mg} / \mathrm{ml}$, Oterop, Belgium) and $5 \mu \mathrm{g}$ bolus of phenylephrine (Phenylephrine $10 \mathrm{mg} / \mathrm{ml}$, Nani Pharmaceutical Pvt, India) were administrated to related groups (ephedrine and phenylephrine groups) until systolic blood pressure exceeded baseline values. Patients with normal systolic blood pressure, after spinal anesthesia, were considered as control group. Severity of headache was assessed through Visual Analog Scale (VAS) with scores from 0 to 10 for representing absence and most severe headache, respectively. Sufentanil and Apotel were administered to alleviate headache during and after surgery, respectively.

\section{Ethical consideration}

The study was carried out in accordance with the Declaration of Helsinki, and the ethics committee of the University of Kermanshah approved the protocols of the study. All patients' consent was obtained and their records were kept confidential.

\section{Data analysis}

Qualitative and quantitative data were analysed and reported as frequency (\%) and mean \pm standard deviation, respectively. Pearson Chi-square test was performed to compare severity of post-surgical headache between different groups. In addition, Kruskal-Wallis test was exploited to compare headache severity during surgery. Also, Spearman's rho correlation coefficient was performed to assess dependency of vasopressor dose to headache severity. $\mathrm{P}$ value $<0.05$ was considered significant. All data were analysed using Stata 12 (StataCorp. 2011. Stata Statistical Software: Release 12. College Station, TX: StataCorp LP).

\section{Results}

The demographic analysis of 105 studied women in this study has been presented in Table 1. The mean value of the age was $29.62 \mathrm{y}$, and no significant difference was observed in the age value of three different groups. Also, the mean value for weight, height and BMI was 76.9, 1.61, and 29.59, respectively, and there was no significant difference between different three groups, as mentioned for age value.

Table 1. Demography of 105 women candidate for cesarean section.

\begin{tabular}{lcll}
\hline & N & Median & Value $^{*}$ \\
\hline Age $(\mathrm{y})$ & & & \\
\hline Control & 35 & 27 & $28.54 \pm 6.670$ \\
\hline Ephedrine & 35 & 29 & $29.89 \pm 7.194$ \\
\hline Phenylephrine & 35 & 30 & $30.43 \pm 4.654$ \\
\hline Total & 105 & 29 & $29.62 \pm 6.269$ \\
\hline
\end{tabular}




\begin{tabular}{llll}
\hline Weight, Kg & & & \\
\hline Control & 35 & 75 & $77.700 \pm 12.2668$ \\
\hline Ephedrine & 35 & 75 & $76.375 \pm 9.8622$ \\
\hline Phenylephrine & 35 & 74 & $76.657 \pm 10.9871$ \\
\hline Total & 105 & 75 & $76.906 \pm 10.9801$ \\
\hline Height, m & & & \\
\hline Control & 35 & 1.62 & $1.6203 \pm 0.04687$ \\
\hline Ephedrine & 35 & 1.62 & $1.6119 \pm 0.05835$ \\
\hline Phenylephrine & 35 & 1.63 & $1.6083 \pm 0.06939$ \\
\hline Total & 105 & 1.62 & $1.6135 \pm 0.05857$ \\
\hline BMI & & & \\
\hline Control & 35 & 29.21 & $29.580 \pm 4.2826$ \\
\hline Ephedrine & 35 & 29.172 & $29.441 \pm 3.9916$ \\
\hline Phenylephrine & 35 & 27.789 & $29.777 \pm 4.8664$ \\
\hline Total & 105 & 28.995 & $29.598 \pm 4.3517$ \\
\hline *Data are presented as mean \pm SD. & & \\
\hline & & \\
\hline
\end{tabular}

As presented in Table 2, the doses of phenylephrine were more than ephedrine; however, this difference was not statistically significant. Also, severity of headache during surgery in groups receiving either ephedrine or phenylephrine was higher than control group, but there was no significant difference between two groups that received vasopressor.

Table 2. Vasopressors dosage and headache severity during surgery among three different groups.

\begin{tabular}{llll}
\hline & N & Median & Value \\
\hline Dosage & & & \\
\hline Ephedrine & 35 & 1 & $1.61 \pm 0.72$ \\
\hline Phenylephrine & 35 & 2 & $2.31 \pm 1.62$ \\
\hline Total & 70 & 2 & $1.95 \pm 1.29$ \\
\hline Headache severity & & & \\
\hline Control & 35 & 0.0000 & $0.3714 \pm 0.49024$ \\
\hline Ephedrine & 35 & 0.5000 & $0.5000 \pm 0.50709$ \\
\hline Phenylephrine & 35 & 0.0000 & $0.4571 \pm 0.50543$ \\
\hline Total & 105 & 0.0000 & $0.4434 \pm 0.49915$ \\
\hline
\end{tabular}

*Data are presented as mean \pm SD.

Systolic blood pressure (mean value) during the surgery for ephedrine group was higher that phenylephrine group $(\mathrm{P}=0.001)$ (Table 3). Also, the difference of systolic pressure between control and phenylephrine groups was significant $(\mathrm{P}<0.001)$, but not for control and ephedrine groups. In addition, respecting to the diastolic pressure, this value was lower in phenylephrine group compare with control $(\mathrm{P}<0.001)$, however, no significant differences were observed between

ephedrine and phenylephrine groups $(\mathrm{P}=0.112)$ or between ephedrine and control groups $(\mathrm{P}=0.97)$. Moreover, assessment of heart rate did not demonstrate any significant difference between all three groups.

Table 3. Hemodynamic stability parameters in relation with vasopressors.

\begin{tabular}{|c|c|c|c|c|c|}
\hline & Mean & Std. error & df & $\begin{array}{l}95 \% \\
\text { interval }\end{array}$ & confidence \\
\hline & & & & $\begin{array}{l}\text { Upper } \\
\text { Bound }\end{array}$ & $\begin{array}{l}\text { Lower } \\
\text { Bound }\end{array}$ \\
\hline $\begin{array}{l}\text { Systolic } \\
\text { pressure }\end{array}$ & & & & & \\
\hline Ephedrine & $116.011^{b}$ & 1.007 & 261.332 & 114.028 & 117.993 \\
\hline Phenylephrine & $110.697^{b}$ & 1.023 & 261.332 & 108.681 & 112.712 \\
\hline Control & $118.958^{b}$ & 1.026 & 261.332 & 116.938 & 120.977 \\
\hline $\begin{array}{l}\text { Diastolic blood } \\
\text { pressure }\end{array}$ & & & & & \\
\hline Ephedrine & $66.886^{\mathrm{b}}$ & 0.901 & 244.2 & 68.661 & 65.112 \\
\hline Phenylephrine & $64.200^{\mathrm{b}}$ & 0.916 & 244.2 & 66.004 & 62.396 \\
\hline Control & $69.657^{b}$ & 0.918 & 244.2 & 71.465 & 67.85 \\
\hline \multicolumn{6}{|l|}{ Heart rate } \\
\hline Ephedrine & $96.906^{\mathrm{b}}$ & 1.569 & 189.651 & 100.001 & 93.811 \\
\hline Phenylephrine & $95.589^{b}$ & 1.594 & 189.52 & 98.732 & 92.445 \\
\hline Control & $97.618^{b}$ & 1.597 & 189.563 & 100.769 & 94.467 \\
\hline
\end{tabular}

The assessment of headache incidence after surgery has been presented in Table 4. Comparing all the groups with each other in a binary manner shows that there was no significant difference between all groups regarding the incidence of headache.

Table 4. Headache-vasopressor cross tabulation analysis* .

\begin{tabular}{lcccc}
\hline & \multicolumn{3}{l}{ Headache } & \\
\cline { 2 - 5 } & Negative & Positive & P value & PR \\
\hline Control & $22(62.9)$ & $13(37.1)$ & 0.466 & 0.812 \\
\hline Phenylephrine & $19(54.3)$ & $16(45.7)$ & & \\
\hline Ephedrine & $17(48.6)$ & $18(51.4)$ & 0.632 & 1.125 \\
\hline Phenylephrine & $19(54.3)$ & $16(45.7)$ & & 0.722 \\
\hline Control & $22(62.9)$ & $13(37.1)$ & 0.228 & \\
\hline Ephedrine & $17(48.6)$ & $18(51.4)$ & & \\
\hline *Data are presented as no. (\%). & & & \\
\hline
\end{tabular}

\section{Discussion}

Spinal anesthesia is known as a standard technique for elective $\mathrm{C}$-section due to its cost effectiveness and less amount of surgical hemorrhage [16,17]. However, the incidence of 
hypotension is major complication of spinal anesthesia, it can be lowered by several ways among which vasopressor are more reliable [18]. In the present study, the severity of incidence of headache between ephedrine and phenylephrine was compared. Following, the effectiveness of each vasopressor on modulation of hypotension was investigated.

As the demographic results of the present study shows, the total mean values of age, weight and height for all the participants were 29.62, 76.9 and 161, respectively. These values were consistent with the demographic results obtained in other studies [19,20] and confirmed the validity of the selected sample. As mentioned in Table 1, the demographic differences between three groups of control, ephedrine and phenylephrine were negligible which implies the similar distribution between all groups, and the independency of vasopressors influence from demographic variables.

Foss et al. studied the effect of phenylephrine and ephedrine on frontal lobe oxygenation during caesarean section with spinal anesthesia, and the results of this study demonstrated the equal effect of both of ephedrine and phenylephrine to maintain the systolic, diastolic and mean arterial blood pressure [13]. Also, in the study conducted by Lundorff et al. comparing two different anesthesia method, ephedrine was used to treat hypotension. In this study, ephedrine did not significantly influenced hemodynamic stability as no differences were observed in the mean arterial pressure [21]. Alkaissi et al. study reinforces the practicality of phenylephrine for the retainment of blood pressure during administration of anesthesia in the spine for optional surgical delivery [22]. On the other hand, the results of our study demonstrated the remarkable effect of ephedrine on systolic and diastolic pressure than phenylephrine. Our findings were in consistent with the study of Aziz et al. which introduced ephedrine as a more effective agent than phenylephrine along with lower side effects [18]. In Kulkarni et al. study ephedrine with spinal injection was more effective in maintaining maternal hemodynamic stability and better neonatal outcome as compared to crystalloid preloading during cesarean delivery [23]. In another study, both of the ephedrine and phenylephrine significantly increased the value of systolic pressure compare with control group, however, in contrast with our results, the influence of phenylephrine was greater than ephedrine [20].

In the study performed by Foss et al. maternal heart rate was not impressed by ephedrine, but it decreased as a result of phenylephrine infusion [13]. The same result was observed regarding the effect of phenylephrine and ephedrine on fetal heart rate [13]. In contrast, the results of our study did not show any significant influence of both ephedrine and phenylephrine on heart rate. In a same way, study of Lundroff et al. did not find any impact on heart rate resulted by ephedrine or phenylephrine [21].

Headache is a complication which has commonly observed in many anesthesia treatments, such as atropin, ondansetron, ephedrine and phenylephrine, and its incidence with respect to different techniques of infusion and different dosage of drug has been studied $[19,24]$. Some studies did not report any incident of headache, even in different anesthesia methods, after using ephedrine to prevent hypotension [21]. According to the results of the present study, although the incidence of headache during surgery in groups of ephedrine and phenylephrine was equal and more than control group, no significant difference was found in three groups with respect to the incidence of drug induced headache. In consistent with our results, the study of Thiangtham and Asampinwat indicated to the similar impact of ephedrine and phenylephrine on the incidence of headache [25]. In contrast with our results, some studies indicated to the higher incidence of headache in ephedrine groups compare with phenylephrine which it might be due to the method or dosage of ephedrine [26,27].

In conclusion, the results of the present study demonstrated that there was no significant difference between ephedrine and phenylephrine with respect to the incidence of headache, neither during nor after surgery. However, the impact of ephedrine on systolic pressure compare with phenylephrine was significant. Thus, regardless the critical alteration in hemodynamic indices, ephedrine and phenylephrine are similar in the term of headache incidence. Finally, we propose a larger sample of candidates to obtain more reliable results.

\section{References}

1. Miller R, Eriksson L, Fleisher L, Wiener-Kronish J, Young W. Millers anesthesia (7th edn.). Philadelphia: Churchill Livingston Elsevier 2010; 1337-1359.

2. Chestnut DH, Wong CA, Tsen LC, Kee WDN, Beilin Y, Mhyre J. Chestnuts obstetric anesthesia: principles and practice: Elsevier Health Sciences 2014.

3. Cooper DW. Caesarean delivery vasopressor management. Curr Opin Anaesthesiol 2012; 25: 300-308.

4. Cyna AM, Andrew M, Emmett RS, Middleton P, Simmons SW. Techniques for preventing hypotension during spinal anaesthesia for caesarean section. Cochrane Database Syst Rev 2006; 002251.

5. Mercier FJ. Cesarean delivery fluid management. Curr Opin Anaesthesiol 2012; 25: 286-291.

6. Ngan Kee WD, Khaw KS, Lau TK, Ng FF, Chui K. Randomised double-blinded comparison of phenylephrine vs. ephedrine for maintaining blood pressure during spinal anaesthesia for non-elective Caesarean section. Anaesthesia 2008; 63: 1319-1326.

7. Ngan Kee WD, Lee A. Multivariate analysis of factors associated with umbilical arterial $\mathrm{pH}$ and standard base excess after caesarean section under spinal anaesthesia. Anaesthesia 2003; 58: 125-130.

8. Thomas DG, Robson SC, Redfern N, Hughes D, Boys RJ. Randomized trial of bolus phenylephrine or ephedrine for maintenance of arterial pressure during spinal anaesthesia for Caesarean section. Br J Anaesth 1996; 76: 61-65.

9. Wang M, Han CB, Qian YN. Comparison of effects in puerpera and fetus with ephedrine and phenylephrine during a cesarean delivery. Zhonghua Yi Xue Za Zhi 2011; 91: 2195-2198. 
10. Veeser M, Hofmann T, Roth R, Klohr S, Rossaint R, Heesen M. Vasopressors for the management of hypotension after spinal anesthesia for elective caesarean section. Systematic review and cumulative meta-analysis. Acta Anaesthesiologica Scandinavica 2012; 56: 810-816.

11. Brooker RF, Butterworth JF, Kitzman DW, Berman JM, Kashtan HI, McKinley AC. Treatment of hypotension after hyperbaric tetracaine spinal anesthesia. A randomized, double-blind, cross-over comparison of phenylephrine and epinephrine. Anesthesiology 1997; 86: 797-805.

12. Loughrey JP, Yao N, Datta S, Segal S, Pian-Smith M, Tsen LC. Hemodynamic effects of spinal anesthesia and simultaneous intravenous bolus of combined phenylephrine and ephedrine versus ephedrine for cesarean delivery. Int J Obstetr Anesth 2005; 14: 43-47.

13. Foss VT, Christensen R, Rokamp KZ, Nissen P, Secher $\mathrm{NH}$, Nielsen HB. Effect of phenylephrine vs. ephedrine on frontal lobe oxygenation during caesarean section with spinal anesthesia: an open label randomized controlled trial. Front Physiol 2014; 5: 812014.

14. Belzarena SD. Ephedrine and etilefrine as vasopressor to correct maternal arterial hypotension during elective cesarean section under spinal anesthesia. Comparative study. Revista Brasileira De Anestesiologia 2006; 56: 223-229.

15. Guo R, Xue Q, Qian Y, Hu Y, Tan J. The effects of ephedrine and phenylephrine on placental vascular resistance during cesarean section under epidual anesthesia. Cell Biochem Biophys 2015; 73: 687-693.

16. Saravanan S, Kocarev M, Wilson RC, Watkins E, Columb MO, Lyons G. Equivalent dose of ephedrine and phenylephrine in the prevention of post-spinal hypotension in Caesarean section. Br J Anaesth 2006; 96: 95-99.

17. Hossain N, Tayab S, Mahmood T. Spinal anaesthesia for caesarean section. J Surg Pakistan 2002; 7: 19-21.

18. Aziz N, Bangash R, Aziz PN, arhaizgar Khan PK. comparison between ephedrine and phenylephrine arison between ephedrine and phenylephrine in the prevention of post spinal hypotension during elective cesarean section. J Med Sci 2013; 21: 27-30.

19. Alonso E, Gilsanz F, Gredilla E, Martinez B, Canser E, Alsina E. Observational study of continuous spinal anesthesia with the catheter-over-needle technique for cesarean delivery. Int J Obstetr Anesth 2009; 18: 137-141.

20. Moslemi F, Rasooli S. Comparison of prophylactic infusion of phenylephrine with ephedrine for prevention of hypotension in elective cesarean section under spinal anesthesia: a randomized clinical trial. Iran J Med Sci 2015; 40: $19-26$.

21. Lundorff L, Dich-Nielsen JO, Laugesen H, Jensen MM. Single-dose spinal anaesthesia versus incremental dosing for lower limb vascular surgery. Acta Anaesthesiologica Scandinavica 1999; 43: 405-410.

22. Alkaissi A, Ussbah Q, Al-Bargouthi A. Prophylactic ephedrine versus phenylephrine for maternal hypotension in women undergoing spinal anesthesia for caesarean section-a randomized double blind clinical trial. J Biomed Sci 2017.

23. Kulkarni KR, Naik AG, Deshpande SG. Evaluation of antihypotensive techniques for cesarean section under spinal anesthesia: Rapid crystalloid hydration versus intravenous ephedrine. Anesth Essays Res 2016; 10: 637-642.

24. Arkoosh VA, Palmer CM, Yun EM, Sharma SK, Bates JN, Wissler RN, Buxbaum JL, Nogami WM, Gracely EJ. A randomized, double-masked, multicenter comparison of the safety of continuous intrathecal labor analgesia using a 28gauge catheter versus continuous epidural labor analgesia. Anesthesiology 2008; 108: 286-298.

25. Thiangtham K, Asampinwat T. Intravenous ephedrine infusion for prophylaxis of hypotension during spinal anesthesia for cesarean section. Songklanagarind Med J 2010; 27: 291-300.

26. Pinto V, Jaysundara N, Abeysundara A, Ekanayake S. Use of phenylephrine as vasopressor of choice to prevent hypotension following spinal anaesthesia in LSCS. Sri Lankan J Anaesthesiol 2009; 16.

27. Sarkar M, Tayade P, Desai P. Phenylephrine versus ephedrine during spinal anesthesia for caesarean section: prospective randomized controlled trial. Ind $\mathrm{J}$ Anaesth Analg 2015; 2: 103.

\section{*Correspondence to}

Parisa Golfam

Department of Anesthesia

Imam Reza Hospital

Kermanshah University of Medical Sciences

Iran 